\title{
From think to remember: how CPs and NPs combine with attitudes in Buryat*
}

\author{
Tatiana Bondarenko \\ Massachusetts Institute of Technology
}

\begin{abstract}
In this paper I investigate a case of factivity alternation in Barguzin Buryat (Mongolic): the verb hanaxa is naturally translated as 'think' when it combines with finite CP clauses, but as 'remember' when it combines with nominalized clauses. I argue that the 'remember' meaning is a result of a pre-existence presupposition associated with the verb's Theme argument: it is presupposed that the Theme exists prior to the event described by the verb. I propose that the factivity alternation arises due to the different ways in which CPs and nominal expressions combine with the verb semantically: while nominals saturate the Theme argument which has the pre-existence presupposition associated with it, CPs combine by modifying the event argument of the verb (Kratzer 2013, 2016; Elliott 2017).
\end{abstract}

Keywords: factivity alternation, clausal embedding, pre-existence presupposition, Mongolic

\section{Introduction}

In this paper I discuss a case of factitivy alternation (Moulton 2009; Abrusán 2011; Özy1ldız 2017) in Barguzin Buryat (Mongolic family). ${ }^{1}$ This language has a verb hanaxa, which, when combines with indicative CPs, (1), is naturally translated as 'think', but when combines with nominalized clauses (NMNs) or nouns, (2), is naturally translated as 'remember, think of'.

$$
\begin{aligned}
& \text { dugar [CP mi:sg9i zagaha эdj-9: g9ž९] han-a: } \\
& \text { Dugar.NOM cat.NOM fish eat-PST COMP think-PST } \\
& \text { 'Dugar } O K_{\text {thought } / * \text { remembered ("thought of") that a cat ate fish.' }}
\end{aligned}
$$

* I would like to thank Sabine Iatridou and Kai von Fintel, Ömer Demirok and Deniz Özyıldız, Elizabeth Bogal-Allbritten, Danny Fox, Martin Hackl, Irene Heim, Mitya Privoznov, Roger Schwarzschild, Sergei Tatevosov, members of the MSU Altaic fieldwork expeditions, and the audiences of LFRG (MIT), WAFL14 and SALT29 for helpful comments and discussion. This study has been supported by Russian Foundation for Basic Research (grant \#19-012-00627 A). All errors are my own.

1 The data presented in this paper has been gathered during fieldwork in village Baraghan (Kurumkan district, Republic of Buryatia, Russia) in 2017-2018. 
proposals that build the inference into the complement clause (Kiparsky \& Kiparsky 1970; Kratzer 2006; Kastner 2015; Hanink \& Bochnak 2017). While I propose that the attitude verb comes with a presupposition, it is not a presupposition that some proposition $\mathrm{p}$ is true, but just a condition on what kind of internal arguments the attitude verb can combine with. This provides a new view of the factive inference as a restriction on an individual argument of the attitude verb.

This paper is structured as follows. In section 2 I provide evidence that the observed inference is indeed a presupposition. Section 3 explores possible alternatives to the proposal argued for in this paper: the ambiguity hypothesis (3.1), the hypothesis that the presupposition is coming from the complement (3.2), and the hypothesis that the presupposition is coming from the matrix verb (3.3). In section 4 I present my proposal. Section 5 provides additional evidence for the proposal, which comes from a different kind of nominalization (nominalized CP), and section 6 concludes the paper.

\section{The observed inference is a presupposition}

As we have seen in (3)-(4), denying the truth of the complement leads to a contradiction when hanaxa takes a nominalization as its complement, but not when it takes a finite clause as its complement. Another contrast can be observed in (5)-(6), where the speaker explicitly says that they are ignorant about the truth of the complement.

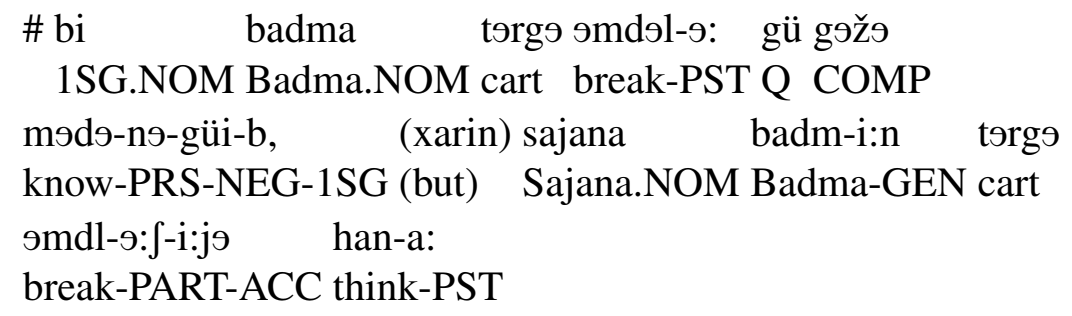

(6) bi badma tэrg९ эmdэl-э: gü gэž९ mэdэ-nэ-güi-b, 1SG.NOM Badma.NOM cart break-PST Q COMP know-PRS-NEG-1SG (xarin) sajana badma tэrgэ эmdl-э: gэžэ han-a: (but) Sajana.NOM Badma.NOM cart break-PST COMP think-PST 'I don't know whether Badma broke the cart, (but) Sajana thought that Badma broke the cart.'

These examples show that the speaker must believe the complement of hanaxa to be true when this verb combines with a nominalization. Examples (7) and (8) show that the observed inference is a presupposition: it survives under question 
and negation. The inference that seems to project in these sentences is that there is an event of Badma breaking the cart in the actual world that existed before the evaluation time. ${ }^{2}$

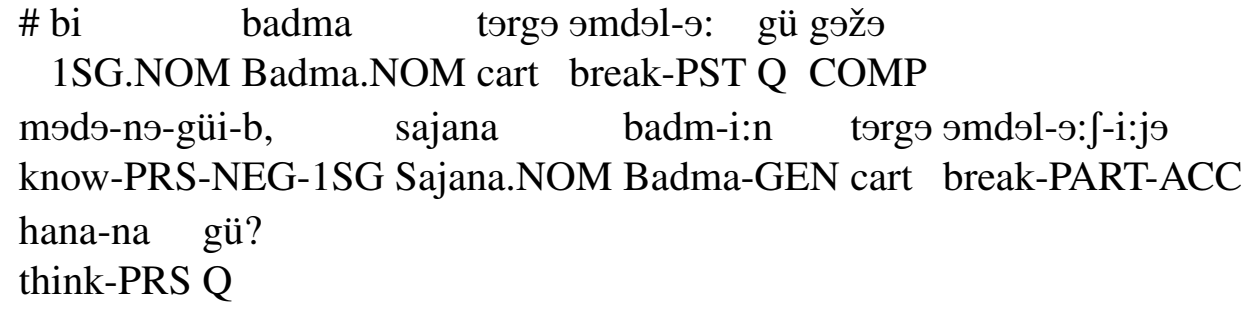

$$
\text { \# badm-i:n tэrgэ эmdэl-э:f-i:jэ sajana han-a:-güi, }
$$

Thus, we can conclude that the inference at hand is a presupposition.

\section{On the source of the presupposition: exploring alternatives}

There could be several hypotheses about the origin of a factive presupposition (see discussion in Özyıldız 2016). In this section, I will discuss three alternatives to my own proposal: the hypothesis that there are two distinct homophonous attitude verbs, a factive and a non-factive one, 3.1, the hypothesis that the presupposition is due to the meaning of the complement clause, 3.2, and the hypothesis that the presupposition is due to the lexical meaning of the attitude verb, 3.3. I will argue that, given the Buryat data, all these alternatives are difficult to pursue.

\subsection{The ambiguity hypothesis}

According to the ambiguity hypothesis, a factivity alternation can arise because a language can have two disctinct but homophonous lexical entries for an attitude verb, a factive and a non-factive one. The factive hanaxa ${ }_{1}$ would always select for a nominal complement, while the non-factive hanaxa 2 would always select for a CP. An empirical argument against this hypothesis can be provided: it is possible for hanaxa to combine with both a nominalization and a CP at the same time, (9).

2 I leave the question of how exactly the presupposition projects in these cases for future research. 
From think to remember

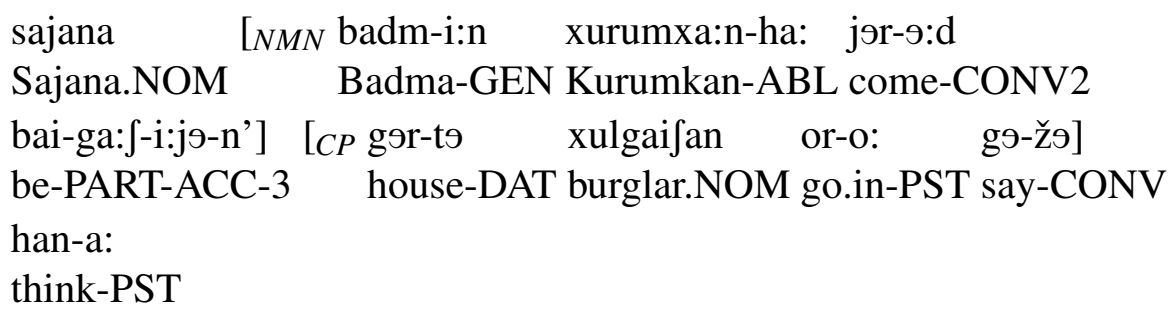

'Sajana remembered ("thought of") of the/an event of Badma returning from Kurumkan, (thinking) that a burglar entered the house.'

In (9) the finite clause describes the thoughts of the attitude holder, while the nominalization describes an event (Badma returning from Kurumkan) which is the topic of Sajana's thoughts. There is an inference that this event has occured, and it happened before the time of Sajana's thinking. Examples like (9) cannot be accounted for under the ambiguity hypothesis, since it presupposes distinct lexical entries for hanaxa when it combines with CPs and when it combines with nominalizations, but here we see a case of it combining with both at the same time.

\subsection{The presupposition comes from the complement}

Another hypothesis is that the factive presupposition arises due to the complement of the verb (Kiparsky \& Kiparsky 1970; Kratzer 2006; Kastner 2015; Hanink \& Bochnak 2017). This hypothesis seems initially attractive due to the cross-linguistic data that suggests that there are correlations found between the syntactic category of the complement of attitude verbs and their factivity (Moulton 2009; Abrusán 2011; Özy1ldız 2017). While attractive, this approach cannot be adapted for the factivity alternation observed in Buryat.

First, it cannot be the case that it is the nominal status that is responsible for the factive presupposition, because the factive presupposition is not observed in all cases when a non-factive verb takes a nominalized complement. For example, when

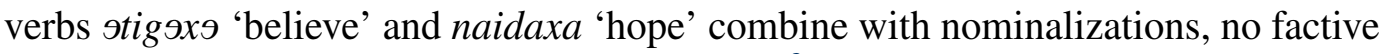
inference arises, hence the felicity of (10)-(11). ${ }^{3}$

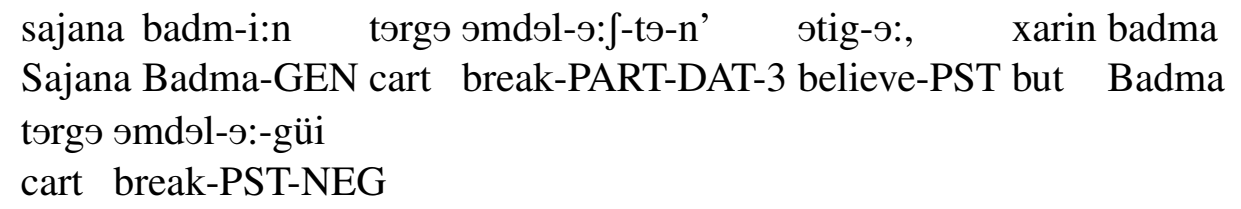

3 Buryat is not unique in allowing non-factive verbs take nominalized clauses without giving rise to the factive inference. For example, the same happens in Turkish (Özyıldız 2017). This suggests that treating nominalizations as factive across the board cannot be the correct solution to factivity alternations. 
'Sajana believes that Badma broke the cart (lit. 'in Badma's breaking the cart'), but Badma didn't break the cart'.

(11) sajana sэsøg-эi xada dэ:rэ gar-a:fa-da naida-na, xarin Sajana Seseg-GEN mountain up go.to-PART-DAT hope-PRS but sэsэg xada dэ:rэ gar-a:-güi

Seseg mountain up go.to-PST-NEG

'Sajana hopes that Seseg went up the mountain (lit. 'in Seseg's going up the mountain'), but Seseg didn't go up the mountain'.

One can note that while hanaxa assigns accusative case to nominalizations, (2), the verbs эtig 9xэ 'believe' and naidaxa 'hope' assign a lexical case — dative. It could then be that the argument structure of these verbs is different: perhaps, the nominalization is not the internal argument of the verbs like stig $9 \times 9$ 'believe' and naidaxa 'hope'. Whether it is a matter of the argument structure or not, we see that just the nominal status of the argument does not suffice for the factive inference to come about.

Second, it also cannot be the case that definiteness is responsible for the observed presupposition in Buryat (see Kastner 2015; Hanink \& Bochnak 2017 for proposals of how definiteness can lead to factivity). The nominalization under consideration does not have to be definite, as (12) shows: there need not be a uniqueness presupposition present. If the nominalization had to be definite, then (12) should have been infelicitous under the reading that the speaker, Seseg and Narana each saw a different event of Sajana's singing a song. ${ }^{4}$

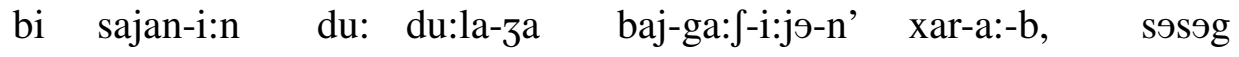
1SG Sajana-GEN song sing-CONV be-PART-ACC-3 see-PST-1SG Seseg sajan-i:n du: du:la-za baj-ga:f-i:jэ-n’ xar-a:, narana Sajana-GEN song sing-CONV be-PART-ACC-3 see-PST Narana

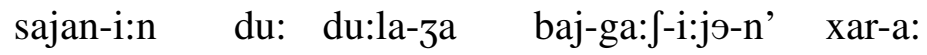
Sajana-GEN song sing-CONV be-PART-ACC-3 see-PST 'I saw Sajana's singing a song, Seseg saw Sajana's singing a song, Narana saw Sajana's singing a song.

OK: The three girls saw each a different singing by Sajana. OK: The three girls all saw the same singing by Sajana.

If it is not the nominal status itself, and not definiteness, then it is not obvious how the nominalized clause could introduce the factive inference into the sentence. I therefore reject the hypothesis that the presupposition comes from the nominalized

4 I am grateful to Deniz Özyıldız for suggesting this diagnostic to me. 
complement. In other words, while data like (1)-(2) suggest that the type of the complement (CP -vs- NP) correlates with the existence of a presupposition, I take this correlation to be an epiphenomenon of the fact that CPs and NPs combine with attitude verbs in different ways, and not as a fact suggesting that the meaning of the nominalization has a factive presupposition written into it.

\subsection{The presupposition comes from the attitude verb}

Another hypothesis is that the factive presupposition is always part of the lexical meaning of the attitude verb. Under this hypothesis, the case when the verb combines with a nominalized clause and has the factive inference is the default case, and what has to be explained is how this presupposition disappears in cases when the verb combines with finite CP clauses. One possibility is to employ the notion of 'plugs' (Karttunen 1973) which can block presuppositions from projecting (Özy1ldı 2016). If one follows Hintikkan semantics for attitude predicates, this would require writing into the meaning of the complement clause the requirement that the proposition that it denotes somehow cancels the presupposition introduced by the verb. I will not adapt 'plugs' as a special tool for cancelling presuppositions. However, I will propose that the observed presupposition is partially due to the lexical meaning of the verb.

To sum up, we have seen that among the sketched out alternative proposals some make wrong empirical predictions (the ambiguity hypothesis and the hypothesis that the presupposition comes from the complement), while others require special tools ('plugs') which we would like to avoid adapting (the hypothesis that the presupposition is part of the meaning of the verb). Note also that all of these alternatives lack an explanation for why 'think' would become 'remember' and not, for example, 'know'. In other words, there seems to be something more than just a factivity inference which is different between the sentences where hanaxa combines with CPs and the sentences where hanaxa combines with nominals, and we would like to have a proposal that captures that.

\section{The proposal: factivity as a consequence of the pre-existence presupposi- tion associated with a Theme argument}

I would like to propose that the factivity alternation in Barguzin Buryat is caused by the argument structure of the verb hanaxa - more precisely, by a pre-existence presupposition that it has associated with its Theme argument.

If we look at non-attitude verbs, we see that internal arguments are in some way special (compared to indirect objects and external arguments): verbs often place restrictions on their interpretation (for example, see Diesing 1992). More specifically, 
they often specify the relation between the temporal interval that corresponds to the existence of the internal argument and the temporal interval corresponding to the event described by the verb:

(13) a. Mary broke a vase. $\Rightarrow$ There existed a vase before the breaking event.

b. Mary read a book. $\Rightarrow$ There existed a book before the reading event.

c. Mary wrote a poem. $\nRightarrow$ There existed a poem before the writing event.

As we see in (13), verbs of destruction (like break) and verbs of use (like read) require their internal arguments to pre-exist the event described by the verb. Verbs of creation (like write), place an opposite requirement: the individual denoted by the internal argument has to not exist before the event described by the verb.

I would like to propose that attitude verbs, just like ordinary verbs, can place constraints on the interpretation of their internal arguments, and these constraints can sometimes lead to factive inferences. ${ }^{5}$ In particular, I would like to propose that Buryat's hanaxa 'think' is similar to verbs of destruction and verbs of use: it requires that its internal argument, which denotes the topic of thoughts (= what the thinking is about), exists before the event denoted by the verb takes place. I would like to argue that the nominalized clauses under consideration denote properties of events, and that they, after combining with (phonologically null) determiners, saturate the internal argument slot of hanaxa. This leads to the presupposition that the/an event described by the nominalization pre-exists the event described by the verb, which leads to the factive inference on one hand, and the "remember" flavor on the other hand: remember $\mathrm{x} \approx$ think of an $\mathrm{x}$ that is presupposed to have existed before the thinking event ${ }^{6}$. I would like to argue that finite CP clauses have a very different path of combining with the verb. They are not saturating the internal argument of the verb, and thus the pre-existence presupposition is not related to their content at all. The main elements of my proposal are thus summarized in (14).

5 I would not, however, want to say that the constraint that hanaxa introduces is exactly identical to the pre-existence inference observed with verbs of destruction and verbs of use in (13), because the inference we see with hanaxa behaves like a presupposition (see section 2), while the inference of the verbs in (13a)-(13b) does not. For example, it seems to not project from under negation:

a. Mary didn't break a vase, because there were no vases around. $\nRightarrow$ There existed a vase before the breaking event.

b. Mary didn't read a book, because there were no books around. $\nRightarrow$ There existed a book before the reading event.

6 I am not suggesting that this is the meaning of remember in English, I am merely hypothesizing that 'remember' is the closest translation of hanaxa due to the presupposition that its internal argument existed before the thinking event. 
From think to remember

\section{(14) Three main elements of the proposal:}

i. Hanaxa 'think' takes an internal (Theme) argument $(\mathrm{x})=$ topic of thoughts, res-argument;

ii. It has a pre-existence presupposition associated with the Theme (x);

iii. NPs combine by saturating the individual argument (x), CPs do not.

My proposal is implemented in the Kratzerian ("decompositional") approach to semantics of attitude predicates (Kratzer 2006, 2013, 2016; Moulton 2009, 2015; Bogal-Allbritten 2016, 2017; Elliott 2017). In particular, I will assume that the quantification over possible worlds comes not from the attitude verb, but from the complementizer (Kratzer 2006) ${ }^{7}$ and that CPs denote properties of contentfull events (Kratzer 2013, 2016; Bogal-Allbritten 2016, 2017; Elliott 2017). My ontological assumptions are the following. I assume that the domain of events, $\mathrm{D}_{v}$, is a subdomain of the domain of individuals $\mathrm{D}_{e}$. I also assume that there is a Content function that takes an event and returns a proposition associated with this event (Kratzer 2013; Elliott 2017). This function is defined only for some events (for example, for events of thinking, believing etc., but not for events of running, climbing etc.). I assume that the events for which the Content function is defined are in the domain $\mathrm{D}_{c v}$, which is a subdomain of the domain of events $\mathrm{D}_{v}$. In the next section (4.1) I discuss the meanings of hanaxa, of the nominalization, and of CP. In sections 4.2 and 4.3 I provide derivations for sentences with the nominalization and with $\mathrm{CP}$ correspondingly.

\subsection{The ingredients}

I propose for the Buryat's verb hanaxa 'think' the semantics in (15):

$$
\begin{aligned}
\llbracket \text { hanaxa } \rrbracket^{w, g}= & \lambda \mathrm{x} \lambda \mathrm{e}: \operatorname{LB}(\tau(\mathrm{x}))<\mathrm{LB}(\tau(\mathrm{e})) . \operatorname{think}(\mathrm{x})(\mathrm{e}) \& \mathrm{e} \text { is in } \mathrm{w} . \\
& (\mathrm{LB}-\mathrm{Left} \text { Boundary (of a time interval), } \\
& \tau-\mathrm{a} \text { function that takes an individual and returns the time } \\
& \text { interval corresponding to the existence of that individual.) }
\end{aligned}
$$

The verb in (15) takes two arguments: an individual (Theme) argument x (i.e., the res argument, what is being thought about) and an event argument e (= the thinking event), and returns 1 iff $\mathrm{e}$ is an event of thinking about $\mathrm{x}$ and $\mathrm{e}$ is in $\mathrm{w}$. This verb has a pre-existence presupposition associated with the Theme (x): the left boundary

7 Elliott (2017) argues that there is no quantification over possible worlds at all: that Content of a given event in a given world is equated with a certain proposition. While I do not adapt this view in my paper, I think that everything I argue for is completely compatible with it. 
of the time interval corresponding to the object of thinking (x) is before the left boundary of the time interval corresponding to the thinking event (e). Thus, while the verb has a presupposition, it is not a factive presupposition that some proposition is presupposed to be true. The presupposition it has is merely a restriction on the type of the individual that the object of the verb denotes.

I assume that the experiencer of the thinking eventuality (the attitude holder) is introduced in the course of the derivation: syntactically, by a Voice projection, and semantically, through the process of Event Identification (Kratzer 1996) with the contentful event argument (e) of hanaxa 'think' — an event that has propositional content associated with it. Within the framework I am assuming, it seems necessary to specify what being the experiencer of a contentful event means and how the entailment patterns of attitude verbs are guaranteed. That is, how do we guarantee that if $\mathrm{B} \subseteq \operatorname{DOX}(\mathrm{x}, \mathrm{w})$ and $\mathrm{A} \subseteq \mathrm{B} \Rightarrow \mathrm{A} \subseteq \operatorname{DOX}(\mathrm{x}, \mathrm{w})$, where $\operatorname{DOX}(\mathrm{x}, \mathrm{w})$ is the set of worlds compatible with beliefs of the individual $\mathrm{x}$ in world $\mathrm{w}$ ? I suggest the following definition of the experiencer of a contentful event: ${ }^{8}$

(16) Definition: $x$ is the experiencer of a contentful event $\mathrm{e}$ in $\mathrm{w}$,

$$
\mathrm{x}=\operatorname{Exp}\left(\mathrm{e}_{c v}\right)_{w} \text { iff } \forall \mathrm{w}^{\prime} \in \mathrm{DOX}_{x, w} \rightarrow \mathrm{w}^{\prime} \in \operatorname{Content}\left(\mathrm{e}_{c v}\right) .
$$

While the definition in (16) could be written as part of the meaning of hanaxa or the Voice head that introduces the external argument, I will, for the purpose of simplification, omit this part of the meaning in the future discussion.

I propose that nominalized clauses under discussion denote properties of events. For example, the denotation of the nominalization we see in (5)-(8) 'Badma's breaking the cart', is represented in (17).

$\llbracket$ Badma's breaking the cart $\rrbracket^{w, g}=\lambda$ e.break(the cart)(e) \& Agent(Badma)(e) $\& \mathrm{e}$ is in $\mathrm{w}$

As we have seen in (12), the nominalization under consideration can be indefinite, and I will use the indefinite reading of the nominalization to illustrate my analysis. I will assume that in cases of indefinite nominalizations, Buryat uses a null existential generalized quantifier with the semantics in (18). This quantifier takes two properties of events and returns 1 iff there is an event that has both of them. Thus, the semantics of the indefinite nominalization is in (19).

$$
\llbracket a \rrbracket^{w, g}=\lambda \mathrm{f} \text { in } \mathrm{D}_{v t} \cdot \lambda \mathrm{q} \text { in } \mathrm{D}_{v t} \cdot \exists \mathrm{e}[\mathrm{f}(\mathrm{e})=1 \& \mathrm{q}(\mathrm{e})=1]
$$

$\llbracket$ a Badma's breaking the cart $\rrbracket^{w, g}=\lambda \mathrm{q}$ in $\mathrm{D}_{v t} \cdot \exists \mathrm{e}[$ break(the cart)(e) \& Agent(Badma)(e) \& e is in w \& $\mathrm{q}(\mathrm{e})=1]$

8 See discussion in Elliott 2017 on how to guaruantee the entailment patterns without appealing to quantification over possible worlds. 
I propose that the Buryat complementizer takes a proposition $\mathrm{p}$ and an event $\mathrm{e}$ as its arguments and returns 1 iff in all worlds compatible with propositional content of e (i.e., in all worlds such that they are in the set of worlds that Content function returns when applied to the event e) the proposition $\mathrm{p}$ is true, (20).

$$
\llbracket \text { that } \rrbracket^{w, g}=\lambda \mathrm{p} \text { in } \mathrm{D}_{s t} . \lambda \mathrm{e} \text { in } \mathrm{D}_{c v} . \forall \mathrm{w}^{\prime}\left[\mathrm{w}^{\prime} \in \operatorname{Content}(\mathrm{e}) \rightarrow \mathrm{p}\left(\mathrm{w}^{\prime}\right)=1\right] .
$$

Thus, CPs denote properties of events. For example, the $\mathrm{CP}$ 'that Badma broke the cart' denotes a set of events such that in all worlds compatible with their propositional content Badma breaks the cart:

$\llbracket$ that Badma broke the cart $\rrbracket^{w, g}=\lambda \mathrm{e}$ in $\mathrm{D}_{c v} . \forall \mathrm{w}^{\prime}\left[\mathrm{w}^{\prime} \in \operatorname{Content}(\mathrm{e}) \rightarrow \exists \mathrm{e}^{\prime}\right.$ [break(the cart)(e') \& e' is in w' \& Agent(e') = Badma]].

In the next sections I will show how, given the denotations proposed in this section, we can derive the factivity alternation in Buryat.

\subsection{Think + Nominalization}

I assume the following LF for a sentence with hanaxa and a nominalization:

\section{The LF of think + indefinite NMN}

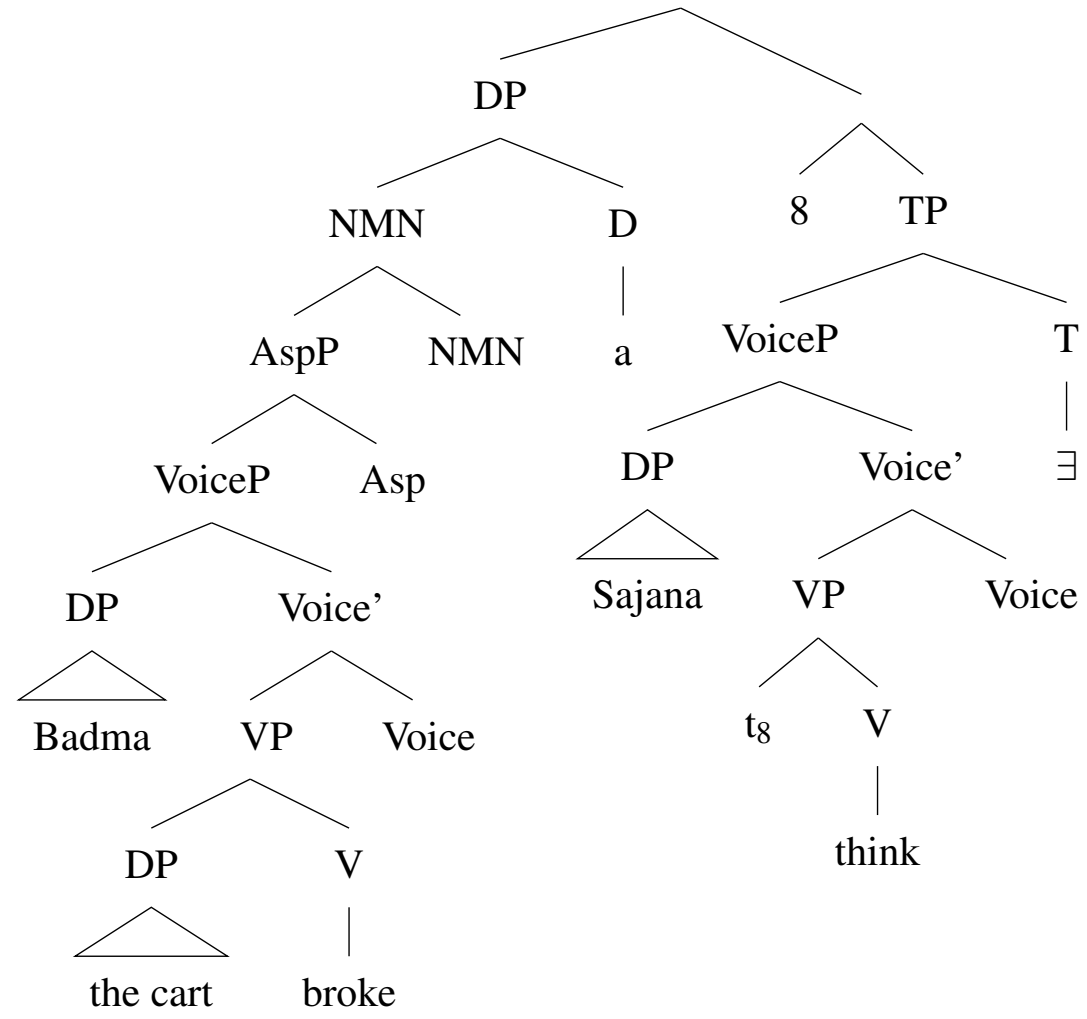


Here we see an indefinite nominalization ('(a) Badma's breaking the cart'), which I assume to undergo QR due to a type mismatch in the object position. ${ }^{9}$ In (22) the nominalization leaves a trace of type e $\left(t_{8}\right)$ in the position it moved out of, and this trace saturates the verb's internal argument (x). I assume that the experiencer of thinking is introduced by the Voice head through Event Identification. Existential closure applies at the level of TP and "closes off" the event variable of the attitude verb, making TP a node of type t. Then Predicate Abstraction applies, which creates a node (the one dominating index 8 and TP in (22)) whose denotation is a set of individuals such that there is an event of thinking about them by Sajana:

$\llbracket 8$ Sajana $t_{8}$ think $\rrbracket^{w, g}=\lambda x \exists \mathrm{e}: \operatorname{LB}(\tau(\mathrm{x}))<\operatorname{LB}(\tau(\mathrm{e})) \cdot \operatorname{think}(\mathrm{x})(\mathrm{e}) \& \mathrm{e}$ is in $\mathrm{w}$ $\& \operatorname{Exp}(\mathrm{e})=$ Sajana.

The indefinite nominalization, (19), combines with its sister, (23), via Function Application $^{10}$, resulting in (24): there are two events in $\mathrm{w}$ : e and e', where e is an event of thinking about e', and e' is an event of Badma breaking the cart.

$\llbracket$ Sajana thinks of (a) Badma's breaking the cart $\rrbracket^{w, g}=1$ iff $\exists \mathrm{e}^{\prime} \exists \mathrm{e}: \operatorname{LB}\left(\tau\left(\mathrm{e}^{\prime}\right)\right)$ $<\operatorname{LB}(\tau(\mathrm{e}))$. [think $\left(\mathrm{e}^{\prime}\right)(\mathrm{e}) \& \mathrm{e}$ is in $\mathrm{w} \& \operatorname{Exp}(\mathrm{e})=\operatorname{Sajana} \&$ break(the cart $)\left(\mathrm{e}^{\prime}\right)$ $\& e^{\prime}$ is in w \& Agent(e')=Badma]

It is also presupposed that e' (Badma's breaking the cart) started existing before e (the thinking event). I propose that this presupposition, which states that the object of thought exists prior to thinking, is responsible for the 'remember / recall / think of' meaning that arises with nominal complements of hanaxa 'think'. ${ }^{11}$

9 Note that QR does not have any other contribution to my analysis apart from resolving the type mismatch. One could alternatively assume that quantificational phrases are interpreted in situ due to the availability of type-shifting; my analysis could be implemented under such a view as well.

10 I assume that although the first argument of an indefinite nominalization is a property of events, it can also take properties which are compatible with being properties of events - like properties of individuals (as mentioned earlier, I assume that $\mathrm{D}_{v} \subset \mathrm{D}_{e}$ ).

11 In (23) and (24) I am being sloppy with the notation concerning the presupposition due to an issue that I do not have a solution to yet: the issue of presupposition projection. According to the meaning I have proposed for the verb hanaxa 'think', it is a partial function: it is only defined if the left boundary of the time interval corresponding to its internal argument is before the left boundary of the time interval corresponding to the eventuality argument. The question is: how does this presupposition project? How does it interact with the existential closure and the existential quantifier inside of the nominalization? While I do not have answers to these questions, the data from section 2 suggest the following desired conditions: the sentence 【Sajana thinks of (a) Badma's breaking the cart $\rrbracket^{w, g}$ should be defined iff there is an event of Badma breaking the cart in w at the time interval whose LB preceeds the LB of the time of evaluation (= time at which the matrix eventuality is evaluated); the sentence should be true iff there exists a thinking event at the time of evaluation about an event of Badma breaking the cart, and false iff there is no thinking event at the time of evaluation about an event of Badma breaking the cart. I leave the question of what the theory of presupposition projection needs to be in order to achieve the desired conditions for the further research. 
Note that in the semantics that I propose the presupposition is about the left boundary only; it does not say anything about how the right boundary of the Theme argument is situated with respect to the thinking event. I assume that in sentences with nominalizations the placement of the right boundary with respect to the matrix event is determined by the aspectual properties of the participle that forms the nominalization. So far we have seen the nominalization formed from the participle with suffix - $a$ : $\int a$, which places the right boundary before the matrix event. But the anteriority of the $-a: \int a$-nominalization is independent of the pre-existence presupposition. For example, nominalizations from the (future) participle with suffix $-x a$ situate the right boundary after the matrix event:

badm-i:n du: du:la-x-i:jø s9s9g han-a:

Badma-GEN song sing-FUT.PART-ACC Seseg.NOM think-PST

'Seseg *thought $/{ }^{O K}$ remembered ("thought of") Badma's (planned for some future time) singing of the song.'

In (25) the verb hanaxa still gets the 'remember' meaning. The event denoted by the nominalization is presupposed to have started existing, which gives rise to the inference that the event was planned or scheduled before the thinking event. ${ }^{12}$ The fact that the presupposition is only about the left boundary becomes even clearer when one looks at proper names as objects of hanaxa: in (26) Badma needs to have started existing before the thinking event, but he doesn't need to be dead for the sentence to be true.

sajana badm-i:jэ han-a:

Sajana.NOM Badma-ACC think-PST

'Sajana *thought /OK remembered ("thought of") Badma.'

Another crucial feature of my proposal is that the nominalizations under consideration do not have a propositional meaning: they are just properties of events. I present two pieces of evidence in favor of this hypothesis.

First, if nominalizations denote predicates of events, then I predict that no quantification over possible worlds is present in sentences containing them. This means that nominalizations should be always interpreted de re and should not describe beliefs of the attitude holder. This turns out to be true. Consider (27).

$$
\begin{aligned}
& \text { badma darim-i:n don türgö:r mafin-a:r jab-a:f-i:jэ } \\
& \text { Badma.NOM Darima-GEN too.much quickly car-INSTR go-PART-ACC } \\
& \text { hana-na, xarin badma } \quad \text { (darima) don türgö:r } \\
& \text { think-PRS but Badma.NOM (Darima.NOM) too.much quickly }
\end{aligned}
$$

12 I leave the details of aspectual interpretation of nominalizations for further research. 
mađin-a:r jab-a: gəžэ hana-na-güi

car-INSTR go-PST COMP think-PRS-NEG

Paraphrase: 'Badma remembers the situation that the speaker thinks of as Darima's driving too quickly, but he doesn't think that Darima drove too quickly. '

In (27) the lexical material of the nominalization and of the CP are identical. If the nominalization denoted a proposition, this sentence would have been contradictory. However, the sentence is felicitous, because the description of the event denoted by the nominalization is the speaker's description, not Badma's.

Second, the distribution of nominalizations suggests that they denote a property of events. Nominalizations can be referred to by the noun $u$ far 'event, situation' and, unlike propositions, can 'happen outside', (28).

a. sajana badm-i:n torgэ эmdэl-э:-i:jø han-a:

Sajana.NOM Badma-GEN cart break-PART-ACC think-PST

'Sajana remembered Badma's breaking the cart.'

b. ... эnэ ufar gaza: bol-o:

this event outside become-PST

'...This event happened outside.'

They also cannot be complements of the predicates that seem to require propositional complements. For example, arsaldaxa 'argue' can combine with CPs, but not with nominalizations. If nominalizations denote properties of events, this is expected: it is not clear how one can "argue an event".

arsaldaxa 'argue'

a. sajana sэsøg xada dэ:rэ gar-a: gэž९ arsalda-na Sajana.NOM Seseg.NOM mountain to go-PST COMP argue-PRS

'Sajana argues that Seseg went to the mountains.'

b. * sajana sэsøg-эi xada də:rэ gar-a:f-i:jø arsalda-na Sajana.NOM Seseg-GEN mountain to go-PART-ACC suspect-PRS

Intended: 'Sajana argues that Seseg went to the mountains.'

\subsection{Think + CP}

I have proposed that the presupposition that hanaxa displays with nominalizations is introduced by the verb: it is a presupposition about the time of existence of the internal argument of the verb. CPs are not subject to this presupposition because 
they are not internal arguments of the verb. They combine with attitude verbs by restricting their eventuality argument and specifying what set of worlds constitutes its Content. The LF for a CP combining with hanaxa is in (30).

\section{(30) The LF of think + CP}

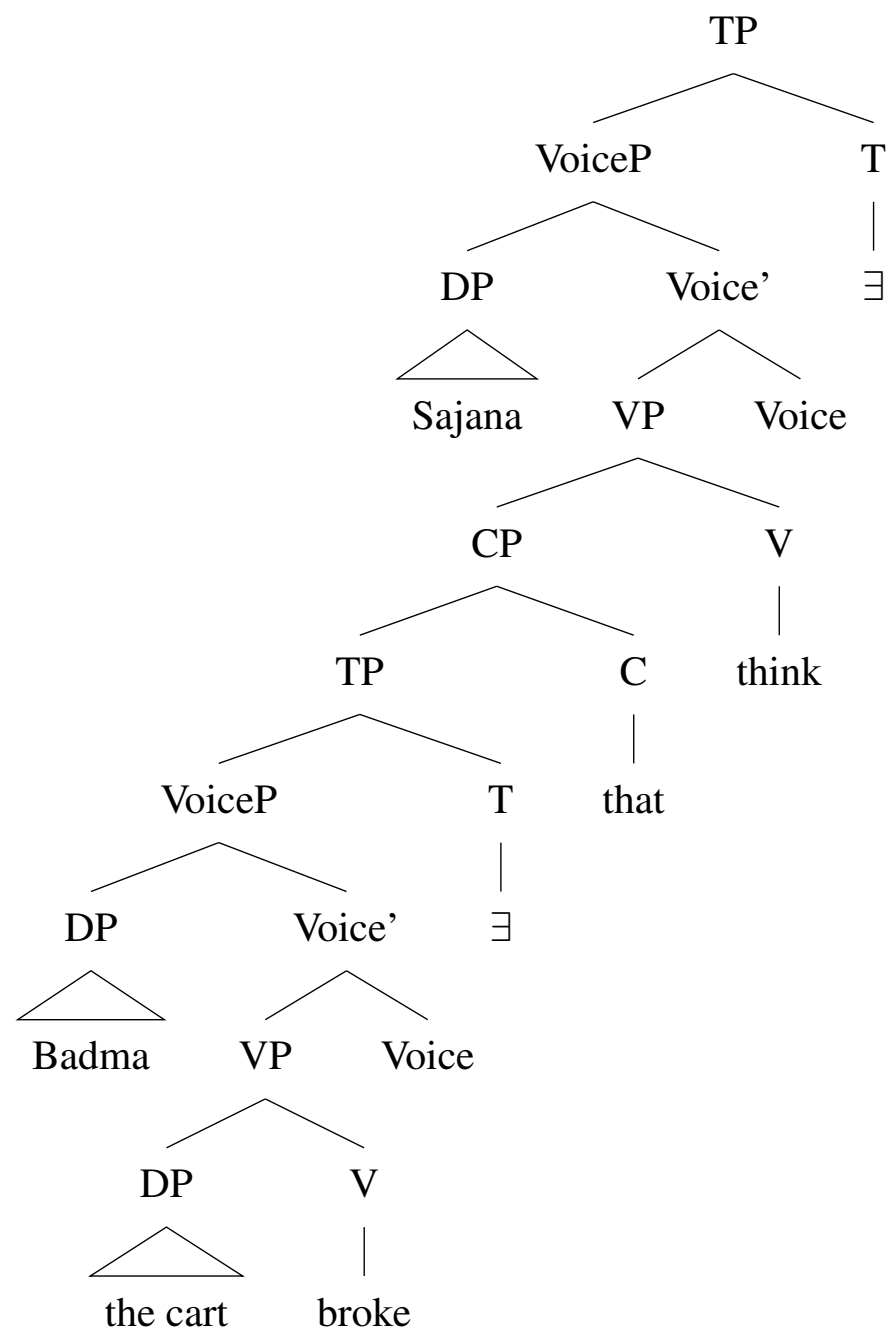

Below I repeat the semantics I propose for the attitude verb hanaxa, (15)=(31), and for the CP clause, $(21)=(32)$. One can see that they can be combined by Event Identification, yielding (33) ${ }^{13}$ : CP here modifies the event argument of the verb.

$$
\llbracket \text { hanaxa } \rrbracket^{w, g}=\lambda \mathrm{x} \lambda \mathrm{e}: \operatorname{LB}(\tau(\mathrm{x}))<\operatorname{LB}(\tau(\mathrm{e})) \cdot \operatorname{think}(\mathrm{x})(\mathrm{e}) \& \mathrm{e} \text { is in } \mathrm{w} .
$$

13 Other semantic principles could be used for combining the verb with CP as well. For example, one could use a modified version of Restrict (Chung \& Ladusaw 2003), or a modified version of Predicate Modification. Here I use Event Identification just because it requires no modification. 
$\llbracket$ that Badma broke the cart $\rrbracket^{w, g}=\lambda \mathrm{e}$ in $\mathrm{D}_{c v} . \forall \mathrm{w}^{\prime}\left[\mathrm{w}^{\prime} \in \operatorname{Content}(\mathrm{e}) \rightarrow \exists \mathrm{e}^{\prime}\right.$ [break(the cart)(e') \& e' is in w' \& Agent(e') = Badma]].

【hanaxa that Badma broke the cart $\rrbracket^{w, g}=\lambda \mathrm{x} \lambda \mathrm{e}: \operatorname{LB}(\tau(\mathrm{x}))<\operatorname{LB}(\tau(\mathrm{e}))$. think(x)(e) \& e is in w \& $\forall \mathrm{w}^{\prime}$ [w' $\in \operatorname{Content}(\mathrm{e}) \rightarrow \exists \mathrm{e}^{\prime}[\operatorname{break}($ the cart)(e') \& $\mathrm{e}^{\prime}$ is in $\mathrm{w}^{\prime} \& \operatorname{Agent}\left(\mathrm{e}^{\prime}\right)=$ Badma]].

We have to assume that at this point of the derivation the Theme argument gets existentially closed, in order to combine with the Voice head (by Event Identification), which introduces the attitude holder. After that the event argument gets existentially closed, resulting in (34).

$\llbracket$ Sajana thinks that Badma broke the cart $\rrbracket^{w, g}=1$ iff $\exists \mathrm{x} \exists \mathrm{e}: \operatorname{LB}(\tau(\mathrm{x}))<$ $\operatorname{LB}(\tau(\mathrm{e}))$. [think(x)(e) \& e is in $\mathrm{w} \& \operatorname{Exp}(\mathrm{e})=\operatorname{Sajana} \& \forall \mathrm{w}^{\prime}\left[\mathrm{w}^{\prime} \in \operatorname{Content}(\mathrm{e})\right.$ $\rightarrow \exists \mathrm{e}^{\prime}\left[\right.$ break(the cart)(e') \& e' is in w' \& Agent( $\left.\mathrm{e}^{\prime}\right)=$ Badma]]]

The presupposition of the verb is still present in the sentence with the $\mathrm{CP},(34)$ : it is defined if there is some $\mathrm{x}$ (topic of thoughts) that existed prior to the thinking event. But this presupposition is undetectable: there is no lexical material that corresponds to the object x. Depending on the context, Sajana's thoughts could be about Badma, or about the cart, or about breakings that happened recently. Note that an event of Badma breaking the cart is only asserted to happen in the worlds which are quantified over, nothing requires the topic of thoughts, which is left implicit, to be Badma's breaking the cart.

One of the questions that arises is whether the pre-existence presupposition is actually present when the verb combines only with CP. While it is difficult to test this, and in this paper I assume it is still present, it is possible to imagine a way such that it would not be present as part of the meaning in sentences with CPs. For this, one would need to assume a strictly neo-Davidsonian approach to argument structure, according to which all arguments, including the internal one, are severed from the verb and are introduced by special functional projections. ${ }^{14}$ Then we could say that the pre-existence presupposition is not written into the lexical meaning of the verb, but is rather part of the meaning of a $\theta_{\text {Theme }}$ head that introduces the internal argument. This move could be beneficial in two ways. First, it would guarantee that in sentences where no nominal has been combined there is no pre-existence presupposition present. ${ }^{15}$ Second, it would obviate the need for an ad-hoc existential closure of the individual argument after the step in (33), where hanaxa combines

14 See Elliott 2017 for argumentation in favor of this approach.

15 Whether this result is what we want is a separate question, and a difficult one: I have not found a way to empirically test whether the pre-existence presupposition is present when hanaxa does not combine with nominals. 
with $\mathrm{CP}$, and before the resulting structure combines with a Voice head. I leave the question of whether this neo-Davidsonian analysis is a better option open for now.

In the proposed analysis CPs are treated as properties of events. Some evidence in favor of this treatment of CPs in Buryat comes from morphology of the complementizer. The complementizer $g$ э`` consists of two morphemes: the root of the verb g9 'say' and the suffix -žs, which is a converbial suffix found in sentential adjuncts, with restructuring verbs, and in analytical verb forms. For example, (35) shows this suffix being present on a temporal adjunct.

$$
\text { ojuna üxibü: türэ-žэ, badma эsэgэ bolo-bo }
$$

Ojuna.NOM child give.birth.to-CONV Badma.NOM father become-PST

'As Ojuna gave birth to a child, Badma became a father.'

If morphology reflects the denotations of these clauses, then the converbial morphology that we see on the complementizer might indicate that finite CPs combine with the predicate in the same way as other -žs-bearing elements do. And given that sentential adjuncts and other converbial clauses can be plausibly analyzed as event modifiers of different kinds, it is not surprising if CPs, which bear the same morphology, are properties of events as well.

\section{Additional supporting evidence: nominalized CPs}

I have argued that nominalizations I have discussed so far (the ones formed from participles, as in (2a)) denote properties of events. In addition to these, Barguzin Buryat also has nominalized CP clauses, (36). ${ }^{16}$

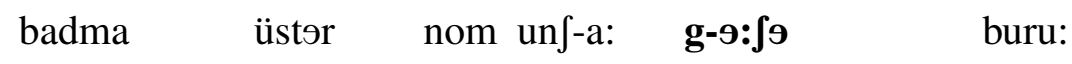

Badma.NOM yesterday book read-PST say-PART.NOM false

'That Badma read a book yesterday is false.'

Nominalized CPs look like a finite clause embedded under the complementizer g9 'say' with the participial morphology and case marking on it. My account of the factivity alternation with hanaxa 'think' makes a prediction about the interpretation of nominalized CPs under this verb. Since I hypothesized that complementizers are sources of quantification over possible worlds, I predict that there should be no factive inference about the proposition embedded by the complementizer. This prediction is borne out, (37).

$16 \overline{\text { I assume that participial nominalizations }}$ are nominalized AspPs or TPs. 


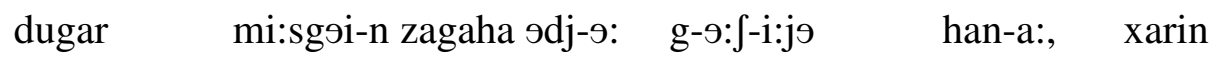
Dugar.NOM cat-GEN fish eat-PST say-PART-ACC think-PST but mi:sggi zagaha эdj-э:-güi cat.NOM fish eat-PST-NEG

'Dugar remembers (the claim) that the cat ate the fish, but the cat didn't eat the fish.'

However, one can see that the verb is still translated as 'remember'. In (37) what Dugar recalls is a claim / rumor / thought that has been previously made. The presupposition of the attitude verb is still there, but it applies not to an event of the cat eating the fish, but to an individual whose content is 'The cat ate the fish'. Thus, it is infelicitous to say explicitly that the proposition $\mathrm{p}$ was not previously mentioned:

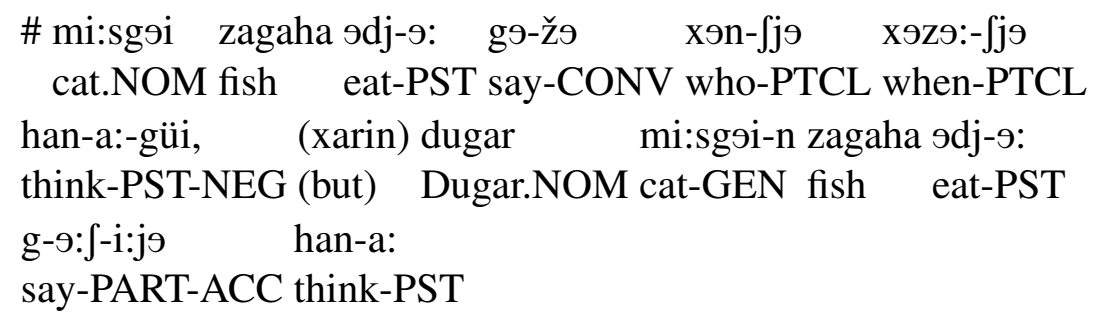

\# 'Noone has ever thought that the cat ate the fish, (but) Dugar remembered (the claim) that the cat ate the fish.'

This is expected if the nominalized CP denotes an individual with propositional content ${ }^{17}$, which saturates the internal argument of the verb, thus being subject to the pre-existence presupposition. As we have seen, this does not lead to a factive inference, (37), since the pre-existence presupposition is associated with the individual with propositional content ('claim'), and not with a much more deeply embedded event of a cat eating the fish.

\section{Conclusion}

In this paper I have proposed, based on data from Barguzin Buryat, that factivity alternations can arise due to the pre-existence presupposition of attitude verbs associated with their internal arguments. If an internal argument of a verb with such a presupposition is saturated by an event-denoting nominalization, we get an inference that the/an event described by the nominalization pre-exists the event described by the verb. The factive inference is part of this inference. Following Kratzer (2013, 2016); Elliott (2017), I have proposed that Buryat CPs combine with the verb by modifying its event argument. Thus, no material inside of $\mathrm{CP}$ is related in any way to the pre-existence presupposition, and no factive inference arises.

17 Bogal-Allbritten \& Moulton (2017) discuss semantics of a similiar nominalization in Korean. 
From think to remember

\section{References}

Abrusán, Márta. 2011. Predicting the presuppositions of soft triggers. Linguistics and Philosophy 34(6). 491-535. doi:10.1007/s10988-012-9108-y.

Bogal-Allbritten, Elizabeth. 2016. Building meaning in Navajo: University of Massachusetts Amherst PhD dissertation.

Bogal-Allbritten, Elizabeth. 2017. Basic pieces, complex meanings: Building attitudes in Navajo and beyond. Invited talk at the Workshop on polysemy and coercion of clause embedding predicates. 39th Annual Meeting of DGfS. Saarbrucken, Germany.

Bogal-Allbritten, Elizabeth \& Keir Moulton. 2017. Nominalized clauses and reference to propositional content. In Sinn und Bedeutung, vol. 21, University of Edinburgh.

Chung, Sandra \& William A Ladusaw. 2003. Restriction and Saturation, vol. 42. MIT press. doi:10.7551/mitpress/5927.001.0001.

Diesing, Molly. 1992. Indefinites. MIT press. doi:10.1017/s0022226700016832.

Elliott, Patrick. 2017. Elements of clausal embedding: Doctoral dissertation, University College London PhD dissertation.

Hanink, Emily \& M Ryan Bochnak. 2017. Factivity and two types of embedded clauses in Washo. In North-East Linguistic Society (NELS), vol. 47, 65-78.

Hintikka, Jaakko. 1969. Semantics for propositional attitudes. In Models for modalities, 87-111. Springer.

Karttunen, Lauri. 1973. Presuppositions of compound sentences. Linguistic Inquiry 4(2). 169-193.

Kastner, Itamar. 2015. Factivity mirrors interpretation: The selectional requirements of presuppositional verbs. Lingua 164. 156-188. doi:10.1016/j.lingua.2015.06.004.

Kiparsky, Paul \& Carol Kiparsky. 1970. Fact. Progress in Linguistics. 143-173. doi:10.1515/9783111350219.143. Manfred Bierwisch and Karl E. Heidolph (eds.) The Hague: Mouton.

Kratzer, Angelika. 1996. Severing the external argument from its verb. In Phrase Structure and the Lexicon, 109-137. Springer. doi:10.1007/978-94-015-86177_5.

Kratzer, Angelika. 2006. Decomposing attitude verbs. Talk given in honour of Anita Mittwoch.

Kratzer, Angelika. 2013. Modality for the 21st century. In The Language-Cognition Interface: the 19th International Congress of Linguists, 179-199.

Kratzer, Angelika. 2016. Evidential moods in attitude and speech reports. Talk given at the 1st Syncart Workshop (University of Siena, July 13, 2016), at the University of Pennsylvania (May 5, 2016), and at the University of Connecticut 
(September 9, 2016).

Moulton, Keir. 2009. Natural selection and the syntax of clausal complementation: University of Massachusetts Amherst PhD dissertation.

Moulton, Keir. 2015. CPs: Copies and compositionality. Linguistic Inquiry 46(2). 305-342. doi:10.1162/ling_a_00183.

Özy1ld1z, Deniz. 2016. Knowledge reports without truth. European Summer School in Logic, Language, and Information (ESSLLI). 184-196.

Özy1ldız, Deniz. 2017. Attitude reports with and without true belief. In Semantics and Linguistic Theory (SALT), vol. 27, 397-417. doi:10.3765/salt.v27i0.4189.

Percus, Orin. 2006. Antipresuppositions. Theoretical and empirical studies of reference and anaphora: Toward the establishment of generative grammar as an empirical science. 52.73.

Tatiana Bondarenko

32 Vassar Street

Massachusetts Institute of Technology

Cambridge, USA, 02139

tbond@mit.edu 